\title{
CAPITAL FLOWS AND THE EFFICIENCY OF CONTROL MECHANISMS
}

\author{
DOI: 10.17261/Pressacademia.2018.1006
}

JEFA- V.5-ISS.4-2018(8)-p.395-403

\section{Meliha Burcu Kines}

Okan University, School of Business and Management Sciences, Department of International Finance, Tuzla, Istanbul, Turkey. burcu.kines@okan.edu.tr, ORCID: 0000-0002-2840-4379

\section{To cite this document}

Kines, M. B. (2018). Capital flows and the efficiency of control mechanisms. Journal of Economics, Finance and Accounting (JEFA), V.5(4), p.395-403.

Permemant link to this document: http://doi.org/10.17261/Pressacademia.2018.1006

Copyright: Published by PressAcademia and limited licenced re-use rights only.

\begin{abstract}
Purpose - The purpose of this study is to investigate the reasons for sudden stop of capital flows in developing and underdeveloped countries and the efficiency of some control mechanisms.

Methodology - In this study, based on the literature review, the fundemental changes of foreign capital flows in home countries, the main reasons causing outflow and the efficiency of basic control mechanisms are investigated theoritically.

Findings- It is observed that at the starting point, there is a need of control mechanisms for short term capital flows in order to eliminate their negative effects on basic macroeconomic indicators.

Conclusion- In our days, the acceleration of capital flows between countries causes debates on current economics theories and policies. Capital flows between countries mainly specified as "hot money" may create severe problems for home countries since they may outflow suddenly for varied reasons. In conclusion, it can be said that in order to acquire a sustainable economic development and growth; some control mechanisms should be applied for foreign short term capital flows and internal resources and foreign direct investments should be encouraged.
\end{abstract}

Keywords: Capital flows, control mechanisms, hot money, foreign direct investments, sudden stop

JEL Codes: O10, O20, O30

\section{SERMAYE HAREKETLERI VE KONTROL MEKANIZMALARININ ETKINLIĞi}

\section{ÖZET}

Amaç- Bu çalışmanın amacı, özellikle az gelişmiş ya da gelişmekte olan ülkelere yatıım yapan sermaye akımlarının kesintiye uğramasının nedenlerini sorgulamak ve aynı zamanda sermaye kontrollerinin etkili olup olmadığı konusunu irdelemektir.

Metodoloji- Bu çalışmada, teorik olarak yabancı sermaye akımlarının girdiği ülkelerde yol açtığı temel değişiklikler, kaçmasına sebep olan başıca unsurlar ve sermaye kontrol mekanizmalarının etkinliği literatür taraması temel alınarak irdelenmektedir.

Bulgular- Kısa vadeli sermayenin temel makroekonomik göstergeler üzerindeki olası olumsuz etkilerini bertaraf etmek için, başlangıç noktasında sermaye kontrol mekanizmalarına ihtiyaç olduğu gözlenmektedir.

Sonuç ve Öneriler- Günümüzde ülkeler arasında artan yoğun sermaye hareketleri, mevcut ekonomi teori ve politikalarının da tartışılmasına sebep olmuștur. Başta "sıcak para" olarak adlandırılan kısa vadeli sermaye akımlarının ülkelere yatırım yapıp, koşullar değişince ani bir şekilde kaçması birçok problemin doğmasına yol açmıştır. Sonuç olarak; sürdürülebilir bir ekonomik kalkınma ve büyümenin temin edilebilmesi için, kısa vadeli yabancı kaynaklara yönelik olarak bazı kontrol mekanizmalarının uygulanması ve iç kaynaklar ile doğrudan yabancı sermayenin teşvik edilmesi gerektiği söylenebilir.

Anahtar Kelimeler: Sermaye hareketleri, kontrol mekanizmaları, sıcak para, doğrudan yabancı sermaye, ani duruş. JEL Kodları: O10, O20, O30

\section{GiRiş}

Özellikle son yıllarda ülkeler arasında artan yoğun sermaye hareketleri, mevcut ekonomi teori ve politikalarının da tartışılmasına sebep olmuştur. Başta "sıcak para" olarak adlandırılan kısa vadeli sermaye akımlarının ülkelere yatırım yapıp, koşullar değişince ani bir şekilde kaçması birçok problemin doğmasına yol açmıştır. Ekonomik büyüme ve kalkınma için sermayeye ihtiyaç duyan az gelişmiş ya da gelişmekte olan ülkeler, sermaye akımlarını teşvik edici ekonomi politikalarını benimsemişlerdir. Her ne kadar sermaye girişi ülkeler açısından olumlu bir unsur olarak kabul edilse bile; doğrudan yatırım 
şeklinde olmayan sermaye akımlarının temel güdüsü kısa sürede kar elde ederek başka ülkelerdeki yatırım alanlarına yönelmektir.

Süresi ne olursa olsun; yabancı sermayenin geldiği ülkede yarattığı başlıca etki, refah seviyesini artırmak yönündedir. Söz konusu olumlu etkinin temel sebepleri; döviz kurunun düşmesi ve dolayısıyla ithalatın artarak ülkeye ucuz malların gelmesi, buna bağlı olarak ülke içindeki enflasyonun aşağıya çekilebilmesi ve yerli para bazında belirlenen milli gelir, kişi başına düşen gelir, dış borç vb. temel makroekonomik göstergelerin iyileşme göstermesidir. Ülke yönetiminde söz sahibi olanlar açısından bakıldığında; bu olumlu tablonun sürdürülebilmesi gayreti içinde oldukları gözlenmektedir. Yanıtlanması gereken soru ise bu işleyişin ne kadar sürdürülebilir olduğunu göz önüne alarak bazı mekanizmalar geliştirmek suretiyle sermaye akımlarını lehte bir duruma çevirmenin mümkün olup olmadığıdır?

Az gelişmiş ve/veya gelişmekte olan ülkeler için kalkınma stratejisi, yerli paranın değerinin düşük tutulması ve ihracatın teşvik edilerek ithalatın kontrol altına alınması olmalıdır. Bununla birlikte; günümüzde birçok az gelişmiş veya gelişmekte olan ülkenin bu stratejiye bağlı kalmayıp tam ters yönde bir politika izlediği görülmektedir. Dışarıdan kaynak girişini sağlamak için, ülke içindeki faizlerin yükselmesini teşvik etmekte ve faiz artışları ülke içinde temel makroekonomik sorunlar da yaratmaktadır. Son 3-4 ay hariç olmak üzere, uzun süredir güçlü seyreden Türk lirası sonucu, sanayimizin rekabet gücünün zayıfladığı ve aynı zamanda üretimimizin de önemli ölçüde ithalata bağımlı hale geldiği gözlenmektedir. Son yıllarda, Türkiye'de büyümenin sıcak paraya endeksli olduğu, dışarıdan kaynak girişi durursa büyümenin sekteye uğrayacağı görülmektedir. İzlenen ekonomi politikalarına bağlı olarak; yurt içindeki tasarruf oranı \%14 seviyesine gerilemiş ve cari açık ise GSYiH'nın \%6 seviyelerine ulaşmıştır. Son dönemde ise; ekonomik faaliyetlerdeki daralma neticesinde cari fazla verilmeye başlanmıştır. Söz konusu veriler bize; Türkiye'nin mevcut ekonomi ve sanayi yapısıyla hedeflenen büyümenin yakalamasının bedelinin yüksek ve sürdürülemez olduğu yönündedir.

Sermaye çıkışına yol açan faktörler arasında, cari açığın belli bir seviyeye gelmesi ile birlikte, ülkedeki döviz borçlanmasının da yükselmesi bulunmaktadır. ${ }^{1}$ Özellikle 1997 yılında yaşanan Asya Krizi'nden sonra döviz kurlarının çok yükselmesine bağlı olarak dış borç yükümlülüklerinin ödenememesi sonucu sermaye akışının durması ve/veya dışarıya kaçması gündeme gelmiş ve bu durum ülkelerin temel makroekonomik dengelerini de sarsmıştır. Başta bankalara ve diğer finansal kurumlara olan döviz kredilerinin ödenememesi sonucunda, finansal sistem de tahribata uğramış ve söz konusu tablo 2001 yılında Türkiye'de de yaşanmıştır. Bu bağlamda, reel sektör ve bankalar arasında yaşanan ödenemeyen kredi problemini çözmek doğrultusunda "İstanbul Yaklaşımı" adı verilen yapılandırma programları geliştirilmiş ve hem banka hem reel sektör firmalarının iflası önlenmeye çalışılmıştır. Ulusal nitelikte olan 2001 yılı Krizi'nden sonra Türk Lirası'nın değer kaybetmesi sonucu yerli firmaların ihracat olanakları artmış ve bunun sonucunda da bir süre sonra ekonomi ihracata dayalı büyüme sağlayabilmiştir. Öte yandan, sermaye hareketlerinin kesintiye uğraması sonucu yaşanan krizlerin büyük bir çoğunluğu ekonomik yapılarındaki kırılganlıklardan ötürü gelişmekte olan ülkelerde görülmektedir. Zaten temel makroekonomik göstergeleri hassas nitelikte olan ve çoğunlukla istikrarsızlıklar ile karşı karşıya kalan söz konusu ülkelerde toparlanma ve düzelme süreci de uzun ve sancılı olmaktadır.

Sermaye hareketleri arasında yer alan doğrudan yabancı sermaye yatırımları ise, gelişmekte olan ülkelerinin ekonomik kalkınmasına ve kaynak ihtiyacına yönelik bir araç olarak kabul edilmiştir. Ancak kimi zaman doğrudan yabancı sermaye yatırımları kapsamında da; yurtdışına kar transferi gündeme gelmekte ve bu durum da ülke içinde elde edilen katma değerin dışarıya yönelmesine yol açmaktadır.

Bu çalışmanın amacı, özellikle az gelişmiş ya da ülkemizin de dahil olduğu gelişmekte olan ülkelere yatırım yapan sermaye akımlarının kesintiye uğramasının nedenlerini sorgulamak ve aynı zamanda sermaye kontrollerinin etkili olup olmadığı konusunu irdelemektir. Sermaye açığı ile karşı karşıya kalan ülkelerin, düşük büyüme ve gelir yaratma unsurlarına bağlı olarak dış finansmana gereksinme duymaları kaçınılmaz bir olgudur. Öte yandan, sermayenin temel motivasyonu giriş yaptığı ülkeleri kalkındırmaktan ziyade, kısa sürede yüksek kar etmek ve yeni yatırım alanlarına yönelmektir. Az gelişmiş ve/veya gelişmekte olan ülkeler açısından sağııkı ve sürdürülebilir bir ekonomik kalkınma için gerekli olan dış finansmana yönelik kimi tedbir ve kontrol mekanizmalarının işlevselliği araştırımalıdır. Çalışmada yer alan literatür taraması kapsamında, sermaye akımlarına yönelik ülke deneyimleri ve yabancı sermaye akımlarının girdiği ülkelerde yol açtığı temel değişiklikler, kaçmasına sebep olan başlıca unsurlar ve sermaye kontrol mekanizmalarının etkinliği irdelenmektedir. Üçüncü bölümünde ise, sermaye kontrollerinin özellikleri ve etkinliği irdelenmiş ve son bölümde de konu ile ilgili sonuç ve öneriler sıralanmıştır.

${ }^{1}$ Calvo, G. A. Izquierdo, A. Mejia, L.F. (2004). On the Empirics of Sudden Stops: The Relevance of Balance Sheets Effects, NBER Working Paper, 10520, 28. 


\section{LITERATÜR TARAMASI}

Ülkeler arasında yoğun olarak görülen sermaye hareketlerinin makroekonomik göstergeler üzerindeki etkisi ve sermaye kontrol mekanizmaları ile ilgili olarak günümüzde akademik çalışmalar yoğunluk kazanmıştır. Serbestçe dolaşan ve ani çıkış yaptığı zaman ülkelerde tahribat yaratan sermayeye yönelik kontrol mekanizmaları ve araçları sorgulanmaya başlanmıştır. Söz gelimi Çin, dışarıdan yüksek tutarda sermaye çeken bir ülke olarak uzun yıllar boyunca parasını dolara karşı düşük tutmuş ve özellikle doğrudan yabancı sermayeyi teşvik edici politikaları uygulamıştır. ${ }^{2}$

Minsky (1993), finansal istikrarsızlık hipotezinde kapitalist bir ekonomik sistemde, reel sektör ile finans sektörü arasında güçlü bir bağ olduğunu vurgulamıştır. ${ }^{3}$ Kapitalist bir ekonomik düzenin sağlıklı işleyişinin sürdürülmesi için gerekli olan unsurun ise, gelecek dönemlere yönelik kar beklentilerinin olduğuna işaret etmiştir.

Yabancı kaynak girişinin sağladığı kısa süreli olumlu faktörlerin etkisi uzun hatta orta vadede ortadan kalkmakta, bunun yanı sıra bu süreçte yerli sanayinin rekabet gücü zayıflamakta ve ihracat da ithalata bağımlı bir hale gelmektedir. Sağlıklı bir iktisat politikası öncelikli olarak; arz yönünü, üretkenlik ve girişimciliği, rekabetçi ve düzgün işleyen bir piyasa ortamında teşvik edici yönde olmalıdır. ${ }^{4}$

Sermaye hareketlerini inceleyen akademik çalışmalar, 1994 yllında gerçekleşen Meksika Tekila Krizi'nden sonra artış göstermiştir. Söz konusu çalışmalarda elde edilen ortak bulgu ise cari işlemler açığının milli gelire oranının \%9-10 seviyesine yükselmesinin krizin bir öncü göstergesi niteliği taşıdığıdır. Bunun yanı sıra; o dönemde Meksika'da olduğu gibi ülke düşük tasarruf oranlarına sahipse; krizlere karşı kırılganlığının daha yüksek olduğu da vurgulanmıştır. Öte yandan, yüksek iç tasarruf oranlarına ve cari işlem fazlasına sahip Asya ülkelerinin de 1997-1998 yıllarında krize girmesi, akademik çalışmalarda elde edilen bulguların yeniden ele alınmasına ve irdelenmesine sebep olmuştur. ${ }^{5}$ Akademik çevrelerde $1997-$ 1998 yıllarında Asya ülkelerinde yaşanan krizin oluşmasında, yüksek tutardaki kısa vadeli dış borçlanmanın da büyük bir etkisinin olduğu hususu genel kabul görmüştür. Sermaye çıkışının hızlandıran etkenler arasında, cari açığın yüksekliğinin yanı sıra ülkedeki dolara bağlı borçlanma artışını olduğu yapılan çalışmalarda belirtilmiştir. ${ }^{6}$

Sermaye hareketleri kapsamında hazırlanan akademik çalışmalarda, özellikle sermayenin kısa vadeli olmasının, ülkeleri krizlere karşı daha kırılgan bir niteliğe büründürdüğüne işaret edilmiştir. Bu noktada sorulması gereken başlıca soru ise sermaye kaçışının neden ülkede istikrarsızlığa yol açtığıdır. Sonuçta, sermaye kaçışı sonucu ekonomide yeni dengeler şekillenecek, yerel paranın değer kaybetmesi neticesinde de ithalat azalırken ülkenin ihracat potansiyeli artacaktır. Söz konusu soruya cevap, ani sermaye çıkışının mali sektörü çok hızı ve olumsuz olarak etkilemesinde aranmalıdır. Özellikle mevduat sahiplerinin durumdan tedirgin olarak bankalardan para çekmesi ve bu durumu takiben reel sektöre kredi kanallarının kapanması üretim sürecini sekteye uğratmaktadır. Bunun yanı sıra, ülke sanayisinin hammadde ve ara mamul bazında yoğun ithal girdi kullanması yaşanan devalüasyon sonucu üretim maliyetlerinin yüksek oranda artmasına sebep olmaktadır. Bu kapsamda, Güney Kore'nin sanayisini negatif dış faktörlere karşı koruyan politikaları uygulaması, ekonomik büyüme modelinin performansında ana unsur olarak kabul edilmektedir. ${ }^{7}$ Amerika Birleşik Devletleri'nde 1929 yılında yaşanan Büyük Buhran krizi süresince çöken iç talep; Keynesyen önlemler ve maliye politikalarının uygulanması sonucu uzun zaman sonra telafi edilebilmiştir. Her ne kadar Büyük Buhran'ın olumsuz etkileri yıllar boyunca sürmüş olsa da; şu an karşılaşılan finansal krizlerin yarattığı tahribat daha fazla ve düzelme süreci daha uzun sürelidir. Bu durumun ana sebebi; günümüzde sermaye akımların çok yoğun olarak ülkeler arasında dolaşması ve buna bağlı olarak para ve maliye politikalarının etkinliğinin azalmasıdır. Sermaye çıkışı sonucu kriz ile karşı karşıya kalan ülkeler de, çıkış yolu olarak Uluslararası Para Fonu'na (IMF) başvurmakta fakat ne yazık ki kemer sıkıcı IMF programları da ekonominin düzelmesi hususunda etkin olamamaktadır. Yürütülen akademik çalışmalarda, cari açık fazlalığının yüksek olmasına ek olarak ülkedeki yabancı para bazlı borçlanmanın artmasının da sermayeyi ürküten ve dışarıya kaçmasına sebep olan bir etken olduğu vurgulanmıştır. ${ }^{8}$ Yapılan akademik çalışmalarda, sermayenin daha çok hangi ülkelere yöneldiği de sorgulanmıştır. Sermaye hareketlerinin daha çok gelişmiş ülkelerden gelişmekte olan ülkelere doğru olduğu gözlemlenmiş ve bu durumun esas olarak gelişmiş ülkelerdeki büyüme hızı ve faiz oranlarından kaynaklandığı tespit edilmiştir. ${ }^{9}$ Öte yandan, bazı akademisyenler akışı

\footnotetext{
2 Brookings Institute, (2011, September). Rethinking Central Banking, Committee on International Economic Policy.

${ }^{3}$ Minsky, H.P. (1993). The Financial Instability Hypothesis. Radical Political Economy, Ed. by Philip Arestis, Malcom Sawyer, NY: Edward Elgar Aldershot.

${ }^{4}$ Paya, M. M. (2013). Küresel Ortamda İktisat Politikaları. İstanbul: Türkmen Kitabevi, 306.

${ }^{5}$ Calvo, G. A. (1998). Capital Flows and Capital Market Crisis: The Simple Economics of Sudden Stops, Journal of Applied Economics, 1(1): 36.

${ }^{6}$ Calvo, G. A. Izquierdo, A. Mejia, L.F. (2004). On the Empirics of Sudden Stops: The Relevance of Balance Sheets Effects, NBER Working Paper, 10520, 22.

${ }^{7}$ Chang, H.J. (1994). The Political Economy of Industrial Policy. New York, NY: St. Martin's Press, 107.

${ }^{8}$ Calvo, G. A. Izquierdo, A. Mejia, L.F. (2004). On the Empirics of Sudden Stops: The Relevance of Balance Sheets Effects, NBER Working Paper, 10520, 36.

${ }^{9}$ Montiel, P. Reinhart, C. M. (1999, August). Do Capital Controls and Macroeconomic Policies Influence the Volume and Composition of Capital Flows? Evidence from 1990's , Journal of International Money and Finance, 18( 4), 624.
} 
belirleyen başlıca faktörün gelişmekte olan ülkenin makroekonomik göstergeleri olduğunu vurgulamıştır. Bu bağlamda, getiriler dikkate alınarak yapılan analizlerde, gelişmekte olan ülkelerin çok daha fazla sermaye çekme potansiyeli taşıdığı ama buna rağmen bu konuda başarılı olamadıklarından da söz etmek gerekmektedir. "Lucas Paradoksu" olarak bilinen bu durum; yüksek getiri ve kar potansiyeline rağmen, neden gelişmekte olan ülkelerin yeterli miktarda kaynak çekemediği sorusuna cevap aramaktadır. ${ }^{10}$ Bu noktada, sermaye için başta insan faktörü olmak üzere tüm makroekonomik dengelerin ve unsurların önem arz ettiğine işaret etmek gerekir.

Bir ülkenin tarihinde borç ödememe durumu varsa, bu hususun yatırımcılar için oldukça olumsuz bir unsur olduğu da yapılan çalışmalarda vurgulanmıştır. Bu duruma paralel olarak, literatürde gelişmekte olan ülkelerin yüksek kar seçeneğine karşın; vasıfsız işgücü, yetersiz hukuki yapı ve eksik kurumsallaşma neticesinde; getiri potansiyeline rağmen sermaye çekmede başarısız olduğu belirtilmiş ve kaynak gereksinimi duyan ülkelerin temel makroekonomik dengelerinin ve uygulanan ekonomi politikalarının önemine işaret edilmiştir. ${ }^{11}$ Makroekonomik göstergeler, uzun vadeli yatırım amacında olan doğrudan yabancı sermaye için belirleyici faktör olurken; kısa vadeli olan sermaye hareketleri için ana unsurun ise makul risk içeren yüksek getiri olduğu görülmektedir. Nitekim, 1994 yılındaki Meksika Krizi'nden sonra, Latin Amerika ülkelerinin, yüksek enflasyon oranlarına rağmen olarak kısa vadeli sermaye çekebilmesi bu tespiti doğrulamaktadır. Kısa vadeli sermayenin temel güdüsü kar imkanı olsa da, nispeten gelişmiş bir finansal sektör ile istikrarlı bir piyasa varlığı da önem arz etmektedir. Sonuç olarak, ani sermaye çıkışlarının önüne geçmek amacını taşıyan ülkelerin önceliği mali istikrarı, piyasa etkinliğini, doğru bir maliye ve para politikasının yanı sıra ihtiyaç duyulan denetim ve kontrol mekanizmalarını da temin etmek olmalıdır. Akademik çalışmalarda, ani ve yoğun sermaye çıkışlarının ülkeler arasında bulaşıcılık etkisine sahip olduğu ve bir ülkede başlayan krizin kısa sürede başka ülkelere de sıçrama özelliği taşıdığının da altı çizilmiştir. ${ }^{12}$

Günümüzde sermaye kontrollerinin, vergi ya da miktar kısıtlaması şeklinde olarak, çok fazla işlevselliğinin olmadığı ve Brezilya gibi geçmişte sermaye kontrolü uygulayan ülkelerin de bu konuda başarılı sonuçlar alamadığı gözlenmektedir. Esas olarak uygulanan sermaye kontrollerinin olumlu etkisi özellikle merkez bankalarının para politikası uygulamalarına esneklik kazandırmak olmuştur. Sonuç olarak, ülkeler refah ve bolluk fazında iken yaratılan katma değerin uzun vadeli, istihdam yaratan yatırımlara yönlendirilmesi ve dış borçlanmaya itibar edilmemesi önem taşımaktadır. ${ }^{13}$

Ülkelerin makroekonomik dengeleri açısından sermaye hareketlerini sorgularken, hangi tür sermayenin krize yol açtığı da irdelenmesi gereken bir husustur. ${ }^{14}$ Sermayenin kısa veya uzun vadeli olması, ülkelerin krizlere karşı kırılganlığını belirleyen önemli bir faktördür. Genel olarak kısa vadeli sermayenin daha çok krizleri tetikleme potansiyeli taşıdığı bilinse bile, özünde her tür dış kaynağın makroekonomik dengeleri sarsabilecek nitelikte olduğu kabul edilmelidir. ${ }^{15}$ Sermaye hareketleri kapsamında bir ülkenin doğrudan yabancı sermayeyi teşvik edici politikalar izlemesi ve bu yolu finansman açığını gidermeye yönelik bir araç olarak görmesi mümkündür. Ancak kimi zaman doğrudan yabancı yatırımların da yurtdışına kar transfer ederek ödemeler dengesi nezdinde sıkıntı yaratabileceği hususu göz ardı edilmemelidir. Doğrudan yabancı sermaye dahi, kar transferi yoluyla sermaye çıkışına sebep olmaktadır.

Ancak yine de, kriz belirtileri ile birlikte, portföy yatırımlarının diğer sermaye hareketlerine oranla daha hızlı ve ani olarak ülkeleri terk ettiği gözlenmektedir. 1997 Asya Krizi'nde, özellikle kısa vadeli banka kredilerinin diğer sermaye türlerine göre daha hızlı ve ani olarak ülkeden çıkış yapan sermaye olduğu gözlenmiştir. ${ }^{16}$ Yapılan çalışmalarda "Ani Duruş" da adı verilen sermaye çıkışlarına yönelik öncelikli tedbir olarak, ülkelerin döviz rezervlerinin yeterli düzeyde bulunmasının gerekliliğine da işaret edilmiştir. ${ }^{17}$

Yüksek tutarda sermaye akışları sonucu ülkede yerli paranın değerlenmesi nedeniyle cari açıkların da zaman içerisinde artmaya başladığı tespit edilmiştir. Bu noktada temel belirleyici faktör, dışarıdan gelen dövizin arz artışına bağlı olarak ulusal kurun aşırı değerlenmesidir. Bu duruma bağlı olarak, ithalat patlaması yaşanırken, ülkelerin ulusal sanayileri ve dolayısıyla ihracat potansiyeli de azalmakta ve ne yazık ki cari açıklar da sürekli artmaktadır. Dışarıdan yüksek tutarda kaynak gelmesi,

${ }^{10}$ Reinhart C. M., Rogoff, K. S. (2004) Serial Default and the Paradox of Rich to Poor Capital Flows, American Economic Review, 94(2) : 5258.

11 Montiel, P. J. (2013, May). Capital Flows : Issues and Policies, Inter-American Development Bank Working Paper Series, IDB-WP-411,11.

12 Kaminsky, G. L., Vega-Garcia, P. (2014, April). Variaties of Sovereign Crises: Latin America 1820-1931, NBER Working Paper Series, 20042, 41.

13 Magud, N. Reinhart, C. M., Rogoff, K. S. (2011). Capital Controls : A Meta Evaluation Approach, Peterson Institute for International Economics, (Çevrimiçi), https://mpra.ub.uni-muenchen.de/30274/

${ }^{14}$ Sula, O. Willett, T. D. (2006). The Reversibility of Different Types of Capital Flows to Emerging Markets, MPRA Paper, 384, University Library of Munich, Germany, (Çevrimiçi), http://mpra.ub.uni-muenchen.de/, 23.

15 Sula, O. Willett, T. D. (2006). The Reversibility of Different Types of Capital Flows to Emerging Markets, MPRA Paper, 384, University Library of Munich, Germany, (Çevrimiçi), http://mpra.ub.uni-muenchen.de/, 16.

${ }^{16}$ Sula, O. Willett, T. D. (2006). The Reversibility of Different Types of Capital Flows to Emerging Markets, MPRA Paper, 384, University Library of Munich, Germany, (Çevrimiçi), http://mpra.ub.uni-muenchen.de/, 23.

17 Sula, O. Willett, T. D. (2006). The Reversibility of Different Types of Capital Flows to Emerging Markets, MPRA Paper, 384, University Library of Munich, Germany, (Çevrimiçi), http://mpra.ub.uni-muenchen.de/, 24. 
bir yandan da yurtiçinde talep ve kredi patlamasına da sebep olmaktadır. Kredi alanında pazar payını artırmayı hedefleyen bankalar ve diğer finansal kurumlar da nispeten teminatı düşük ve riski yüksek krediler tahsis etmeye yönelmektedirler. Ancak ne yazık ki bu durum sürdürülebilir bir olgu değildir. Kendi güvenliği için temel makroekonomik göstergeleri analiz eden sermayenin eninde sonunda cari açıkların belli bir seviyeye ulaşması ile birlikte dışarı kaçma yolunu seçecektir. Ülkenin riskinin taşınamaz boyutlara geldiğini düşünen yatırımcılar sürü psikolojisi dürtüsüyle aniden ülkeden kaçma yolunu seçmektedirler.

Sermaye hareketleri çerçevesinde sorgulanan bir başka husus da, para kaçışı başlamadan önceki eşik değerin ve/veya temel göstergenin ne olduğu sorusudur. Bu sorunun yanıtı ise, cari açık oranının milli gelirin belli bir seviyesine erişmesinde aranmalıdır. Örneğin, 1994 yılında yaşanan Meksika Krizi'nin hemen öncesinde cari açığın milli gelire oranın \%9 mertebelerinde bulunduğu görülmektedir. ${ }^{18}$

Bunun yanı sıra, fon sahiplerinin yatırım yapacakları ülke hakkında güncel ve doğru bilgi sağlama olanağı yoksa, bu durum da sermaye için caydırıcı bir faktör olarak ele alınmalıdır.

Bazı akademik çalışmalar kapsamında da, bölgesel farklar üzerinde de durulmuştur. ${ }^{19}$ Asya ülkelerinin daha çok doğrudan yatırım çekmesi, Latin Amerika ülkelerinin ise kısa vadeli sermaye akışlarına maruz kalması akademik çevrelerde sorgulanan bir unsur olmuş ve bu durumun nedenleri araştııılmıştır. Bu konuda hazırlanan bir çalışmada, kısa vadeli sermaye hareketleri yönünden ülkelerin kredi notlarının yanı sıra fiyat-kazanç oranlarının da önem taşıdığı belirtilmiştir. ${ }^{20}$

Son yıllarda, gelişmekte olan ülkelere olan sermaye akışlarının artmasının önemli bir nedeni de, likiditenin bollaşması ve özellikle gelişmiş ekonomilerde faiz oranlarının da düşük seviyelerde seyretmesidir. 2008 yılında başlayan Küresel Kriz'i takiben, gelişmiş ülkelerin merkez bankalarının piyasalara önemli miktarda likidite vermesi, söz konusu ülkelerde faizlerin çok düşük seviyelere inmesine yol açmış ve bunun sonucu olarak gelişmekte olan ülkelere artan oranda bir sermaye akışı olmuştur. Bu durumdan ülkemiz de etkilenmiş, iç piyasada faizlerin göreceli olarak yüksek olması nedeniyle, ülkemiz Küresel Kriz sonrası büyük miktarda dış kaynak akışı ile karşı karşıya kalmıştır.

Yoğun dış kaynak girişi, özellikle finansal kurumları ve piyasaları kırılgan bir noktaya taşımıştır. Yaşanan bankacılık krizlerinin başlıca öncü göstergesinin ise kısa vadeli döviz borçların milli gelire oranı olduğu görülmektedir. ${ }^{21}$ Gelen sermayenin yatırım mı yoksa tüketim harcamalarını mı uyardığı konusu, yerli kurun değer artış düzeyini belirleyen temel faktör olarak görülmelidir. Bir başka deyişle, eğer gelen sermaye yatırım harcamaları yerine daha çok tüketim harcamalarını artırıyorsa, yerli kurun çok daha fazla artış kaydettiği gözlenmiştir. Bu bağlamda, dış kaynaklı sermayenin Asya ülkelerinde yatırıma yönelirken, Latin Amerika ülkelerinde ise tüketimi körüklediği görülmüştür. Son yıllarda ülkemize giriş yapan sermaye hareketlerinin de iç tüketimi artııı ı nitelikte olduğu ve büyümenin bu kanalla sağlanabildiği konusunda görüş birliği bulunmaktadır. Geçmiş yıllarda, yabancı kaynağın sebep olduğu iç talep ve kredi patlamasının önüne geçmek için, Asya ülkeleri sıkı maliye ve sterilizasyon politikalarını uygulamaya koymuştur.

Gelen sermayenin kısa vadeli nitelikte kalmasının ve uzun vadeli doğrudan yatırıma dönüşmemesinin en önemli sebebi, ülkelerin makroekonomik dengelerine ve yürürlükte olan ekonomi politikalarına olan güven hissidir. Olumlu seyrin süreklilik arz etmeyeceğini dikkate alan sermaye sahipleri, söz konusu ülkelere geçici olarak giriş yapmakta ve bir süre sonra da hedeflenen kara ulaşıp ülkeyi terk etmektedir. Ülkeden çıkış yaptıklarında ise, zaten hassas bir denge üzerinde kurulmuş olan temel makroekonomik göstergeler hızla bozulmakta ve olumsuz gidişat sermaye kaçışını da hızlandırmaktadır. Çoğu zaman tahribatın gücü ve hızı karşısında alınan geçici önlemler de güvensizliği artırmakta ve bir panik havasının doğmasına sebep olmaktadır.

Sonuçta; günümüzde sermaye hareketleri ve kontrol mekanizmaları üzerine hazırlanan akademik çalışmaların yoğunlaştığı görülmektedir. Bu noktada; sermaye kontrollerinin ise ne zaman, bir başka deyişle fonların ülke girişinde mi yoksa çıkışında mı uygulanacağı konusu da önem arz etmektedir. Öte yandan; yapılan çalışmalar, sermaye kontrollerinin etkin olma durumunun zamanlamadan ziyade, giriş yaptığı ülkedeki ekonomi politikalara göre şekillendiğini belirtmektedir. Bu konuda Brezilya, karşımıza önemli bir örnek olarak çıkmaktadır. 1990'lı yıllarda fon akımlarının kontrolü için Tobin vergisini yürürlüğe sokan Brezilya başarısızlığa uğramıştır. Söz konusu başarııılı̆̆ın temel nedeni; Brezilya Merkez Bankası'nın o sırada uyguladığı sterilizasyon programıdır. Sermayenin ani kaçışını durdurmak için bir araç olarak belirlenen verginin etkinliği, sterilizasyon programı sonucu faizlerin yükselmesiyle azalmış ve vergi uygulanmasına karşın ülkeye fon girişi devam

\footnotetext{
18 IMF verisi.

${ }^{19}$ Montiel, P. Reinhart, C. M. (1999, August). Do Capital Controls and Macroeconomic Policies Influence the Volume and Composition of Capital Flows? Evidence from 1990's, Journal of International Money and Finance, 18( 4), 626.

${ }^{20}$ Shuhan, P. Claessens, S. Mamingi, N. (1993, July). Equity of Bond Flows to Asia and Latin America The Role of Global and Country Factors, WPS 1160, International Economics Department, The World Bank, 21.

${ }^{21}$ Reinhart C. M., Rogoff, K. S. (2013, December). Financial and Sovereign Debt Crises : Some Lessons Learned and Those Forgotten, IMF Working Paper, WP/13/266, 7.
} 
etmiştir. ${ }^{22}$ Akademik çevrelerde; piyasa işleyişi ile uyumlu olsa bile, sermaye kontrollerinin kısmen kısa vadede etkin olabileceği, uzun vadede ise sermaye kontrolleri uygulamasının başarılı olamayacağı anlayışı geçerliliğini korumaktadır.

Aşağıdaki Tablo 1'de görüleceği gibi, yukarıda detayı verilen ve sermaye akımları üzerine çalışan akademisyenlerin sermaye hareketleri ile ilişkilendirdikleri ana kavramları özetlemektedir:

Tablo 1: Literatür Çalışması Kapsamında Sermaye Akımları ve Ana Kavramlar

\begin{tabular}{|ll}
\hline Minsky (1993) & Finansal istikrarsızlık hipotezi \\
Paya, M.M. (2013) & Üretkenlik ve girişimcilik \\
Calvo, G.A. (1998) & Cari fazla \\
Calvo, G.A., Izquierdo, A., Mejia, L.F. (2004) & Dolara bağlı borçlanma artışı \\
Chang, H. J. (1994) & Yoğun ithal girdi \\
Montiel, P. J., Reinhart C. M. (1999) & Büyüme hızı ve faiz oranları \\
Reinhart, C. M., Rogoff, K. S. (2004) & İnsan faktörü \\
Montiel, P. J., (2013) & Temel makroekonomik dengeler \\
Kaminsky, G. L., Vega-Garcia, P. (2014) & Bulaşıcılık etkisi \\
Magud, N., Reinhart,C.M.,Rogoff, K. S. (2011) & Para politikası esnekliği \\
Sula, O., Willett, T. D. (2006) & Sermaye türü \\
Montiel, P. J., Reinhart, C. M. (1999) & Bölgesel farklar \\
Shuhan, P., Claessens, S., Mamingi, N. (1993) & Fiyat-kazanç oranları \\
Reinhart, C. M., Rogoff, K. S. (2013) & Kısa vadeli döviz borçların milli gelire oranı \\
Magud, N. E., Reinhart, C. M., Vesperoni, E.,R. (2012) & Tobin vergisi \\
\hline
\end{tabular}

\section{SERMAYE KONTROLLERININ ÖZELLIKLERI VE ETKINLIĞi}

1990 'lı yıllarda uygulamaya başlanan liberal ekonomi politikalarının, istikrar sağlaması hedeflenirken tam tersine özellikle az gelişmiş ve gelişmekte olan ülkelerde belirsizlikleri ve dalgalanmaları arttırdığı gözlenmektedir. ${ }^{23}$ i̇zlenen liberal iktisat politikaları çerçevesinde denetim ve kontrol mekanizmaları gevşetilmiş; sermayenin ülkeler arasında serbestçe dolaşmasına imkan tanınmıştır. Bir ülkeye gelen sermayenin kısa vadeli olmasının ve doğrudan yatıııma yönelmemesinin en büyük sebebi, ülkelerin makroekonomik dengelerine ve aynı zamanda yürürlükte olan ekonomi politikalarına duyulan inanç ve güvendir. Uygulanan iktisat politikalarının geçici, günü kurtarmaya yönelik önlemler kapsamında değerlendiren fon sahipleri; ülkelere çoğunlukla kısa vadeli olarak giriş yapmakta ve yeterli düzeyde kar elde edince de ülkeyi terk etmektedirler.

Söz konusu ülkelere gelen sermaye daha çok likiditesi yüksek finansal araçlara yatırım yapmakta ve özellikle gelişmiş ülkelere oranla yüksek seyreden faiz avantajından faydalanmayı hedeflemektedir. Bu durum, esasında az gelişmiş ve/veya gelişmekte olan ülkelerin açısından kısa vadeli bir finansman kaynağını temin edebilmek için ağır bedeller ödenmesi gerektiğine işaret etmektedir. Bu olgunun bilincinde olarak; kalkınma ve büyüme için dış kaynağa gereksinim duyan ülkelerin öncelikli olarak kısa vadeli, geçici sermayeye karşı bazı kontrol mekanizmaları ve vergi uygulamaları geliştirebilmeleri gerekmektedir.

Olası sermaye kontrollerinin başlıca iki önemli niteliği göze çarpmaktadır: 1) Asimetrik yapıları ve 2) Geçici olmaları. ${ }^{24}$ Sermaye kontrollerinin asimetrisi, uygulamanın çoğunlukla girişlerde yapılırken, çıkışlarda uygulanmaması hususundan oluşmaktadır. 1990'lı yıllardan itibaren ülkelerin sermaye kontrolleri için değişik araçlar kullandığı gözlenmektedir. Söz gelimi; 1995 yılında Çek Cumhuriyeti kısa vadeli sermayeye yönelik olarak miktar kısıtlamasında bulunmuş, Brezilya ise 1993-1997 yılları arasında yabancı sermaye üzerine vergi koymuştur. 1995-1997 yılları arasında Tayland, ulusal bankaların off-shore borçlanmalarını sınırlama yoluna gitmiş, Şili ve Kolombiya da sermayeyi vergilendirmiştir. Sermaye kontrol araçlarının geçici olması ise, sermaye girişlerinin yavaşlaması ve/veya azalması sonucu, uygulamanın da azaltılması ya da tamamen ortadan kaldırıması durumunu tanımlamaktadır.

\footnotetext{
${ }^{22}$ Magud, N.E. Reinhart, C. M. Vesperoni, E.R. (2012, February). Capital Inflows, Exchange Rate Flexibility and Credit Booms, IMF Working Paper, 19.

${ }^{23}$ Cassidy, J. (2009). How Markets Fail: The Logic of Economic Calamities. New York, NY: Farrar, Straus and Giroux, 22.

${ }^{24}$ Magud, N. E., Carmen M. R., Rogoff, K. S. (2011, February). Capital Controls : Myth and Reality-A Portfolio Balance Approach, NBER Working Paper, 18.
} 
Sermaye kontrollerinden bir tanesi olan ve merkez bankalarının uyguladığı sterilizasyon programlarının da, yerel faizleri artırıcı etkisi bulunduğu için, kısa vadeli yabancı sermayeyi özendirici özelliğe sahiptir. Örneğin, 1991 yılında Kolombiya'da ve 1991-1992 yılları arasında ise Malezya'da devreye alınan sterilizasyon uygulamaları kısa vadeli dış kaynak sermaye akımlarının belirgin bir şekilde artmasına yol açmıştır.

Sermaye girişlerinin sebep olacağı kredi patlamasını önlemek amacıyla merkez bankaları zorunlu karşılık oranlarını artırmak yolunu da tercih edebilir. Örneğin, Şili ve Malezya'nın dış kaynakların krediler üzerindeki baskısını hafifletmek için bu aracı kullandıkları gözlenmiştir. Ancak, söz konusu kontrol mekanizmasının sadece kısa vade içinde etkili olduğu belirtilmelidir. Bu durumun yanı sıra, finansal piyasalar ve kurumlara yönelik etkin bir düzenleme ve denetleme uygulamasının da ülkeleri yoğun sermaye akımlarının yaratacağı olumsuz unsurlardan kısmen koruyabileceği hususu da önem taşımaktadır.

Sermaye kontrol mekanizmaları arasında bulunan bir başka araç ise, sıkı maliye politikası uygulamasıdır. 1988-1991 yılları arasında Tayland, sıkı maliye politikalarını kullanarak, dış kaynak girişlerinin yaratacağı tahribatı hafifletme yolunu seçmiştir. Bununla birlikte; sıkı maliye politikaları izlemek ve bu kapsamda kamu harcamalarını kısmak da ekonomik olduğu kadar politik bir karar niteliğinde olup, uygulaması ve başarılı sonuç alınması toplumsal uzlaşı ve kararlılık gerektirmektedir. ${ }^{25}$

Görüldüğü gibi, sermaye kontrollerinin bir mertebeye kadar etkin olabileceği belirtilen örneklerden tespit edilebilmektedir. Öte yandan, sermayenin ani çıkışlarını ve olumsuz etkilerini bertaraf etmenin en geçerli ve başarılı yolu, yatırımcılar nezdinde ülkenin güvenirliliğinin sağlanması ve işlevsel bir yatırım ortamının tesis edilmesi bir ön koşul olarak kabul edilmelidir. ${ }^{26}$

Uygulanan sermaye kontrollerinin sermaye üzerindeki etkisi incelendiğinde; özellikle gelen fonların yapısını ve aynı zamanda miktarını değiştirdiği görülmektedir. Bu bağlamda, neden sermaye girişlerine yönelik bir kısıtlamaya ihtiyaç duyulduğu sorusunu vurgulamak gerekmektedir. Sonuçta; kısa ya da uzun olsa da sermaye girişinin iç talebi de artırarak ekonomik canlanma sağladığı görüşü gündeme gelebilir. Sorunun yanıtı ise, gelen sermayenin çoğunlukla tüketim harcamalarını artırması durumunun da sürdürülemez olduğu ve uzun vadede ülkenin makroekonomik dengelerini bozmasında yatmaktadır. 2008 Küresel Kriz sonrası; ülkemize yönelen likidite sonucu iç talep körüklenirken zaman içerisinde üretim cephesi zayıflamış; mal ve hizmet açığı ithalat yoluyla karşılanmış ve temel makroekonomik dengeler ise sarsılmıştır. Bu noktada vurgulanması gereken bir diğer husus ise; izlenen ekonomi politikaları sonucu böyle bir yapının oluşması halinde düzeltme araçlarının ve politikalarının da zor ve zaman alıcı olduğudur. Günümüzde; akademik çevre ve iş dünyası tarafından sık olarak dile getirilen yapısal önlemler uygulamaya konmadan, yıllar içerisinde oluşan tahribatı gidermek olası görünmemektedir. Yapısal reformlar ise köklü değişiklikler ve uygulamalara yol açtığından; izlenen politikaların sadece uygulayıcılar tarafından değil toplumun geniş kesimleri nezdinde de destek görmesi gerekmektedir. Toplumun ancak uzun vadede sonuç alınabileceğine inanması ve güvenmesi; yapısal reformların başarılı olabilmesi için bir önkoşuldur. Sonuç olarak; kısa vadeli sermayenin olası olumsuz etkilerini bertaraf etmek için başlangıç noktasında sermaye kontrol mekanizmalarına ihtiyaç olduğu gözlenmektedir.

Sermaye kontrolleri kapsamında özellikle verginin bir araç olarak etkinliğini belirlemek için, söz konusu verginin cari işlemler dengesine yönelik etkisini belirlemek gerekmektedir. Bununla birlikte, bir verginin arzulanan etkiyi gösterebilmesi için vergi oranının çok yüksek seviyede bulunması da önemli bir gerekliliktir. Ayrıca bu noktada zamanlamanın da önem taşıdığı da vurgulanmalıdır. Gereğinden fazla uzun sürede yürürlükte kalan verginin de makroekonomik dengeleri olumsuz yönde etkilediği göz önünde bulundurulmalıdır. Yapısal reformlar içerisinde önemli bir ağırlığa sahip olan verginin, toplum refahını artıracak şekilde düzenlenmesinin ve etkin bir vergi sisteminin oluşturulmasının az gelişmiş ve/veya gelişmekte olan ülkeler açısından önemi tartışılmazdır. ${ }^{27}$

\section{SONUÇ VE ÖNERILER}

Günümüzde sermaye hareketleri, ülke ekonomilerini şekillendiren önemli bir faktör olarak ele alınmakta ve hem akademik hem siyasi çevrelerde sık olarak sorgulanmaktadır. Gerek az gelişmiş ve/veya gelişmekte olan ülkelerde ekonomik büyüme ve kalkınma için kaynağa gereksinim olması, gerek 2008 Küresel Krizi'ni takiben dünyada artan likiditenin kar motivasyonu, sermaye hareketlerinin artmasına yol açmıştır. ABD ekonomisini canlandırma kapsamında Merkez Bankası tarafından piyasalara enjekte edilen paranın tercihi ise yüksek faiz sunması nedeniyle çoğunlukla Türkiye gibi gelişmekte olan ülkeler olmuştur. Kısa vadede sorunsuz bir şekilde işleyen söz konusu ekonomik yapı, uzun vadede gelişmekte olan ülkelerin daha fazla dış finansmana bağımlı hale gelmesine yol açmıştır. Zamanında özellikle kısa vadeli sermayeye karşı önlem almayan ülkelerin de temel makroekonomik dengelerinin bozulduğu ve hatta gerek finansal gerek reel sektör kaynaklı krizler ile karşılaştı̆̆ı gözlenmiştir.

\footnotetext{
${ }^{25}$ Acemoğlu,D. (2009). Introduction to Modern Economic Growth, New Jersey: Princeton University Press, 777.

${ }^{26}$ Shuhan, P. Claessens, S. Mamingi, N. (1993, July). Equity of Bond Flows to Asia and Latin America The Role of Global and Country Factors, WPS 1160, International Economics Department, The World Bank, 21.

${ }^{27}$ Rodrik, D. (2007). One Economics Many Recipes : Globalization, Institutions and Economic Growth, New Jersey : Princeton University Press, 17.
} 
Öte yandan, dışarıdan gelen sermayenin ulusal sanayini iki yönden olumsuz etkilediği görülmüştür. İlk olarak; ucuzlayan kurlar neticesinde daha fazla hammadde ve ara malının ithal edilmesi ve ikinci olarak da nihai sanayi ürünlerinin de fiyat avantajı nedeniyle daha çok dışarıdan satın alınmasıdır. Ortaya çıkan tabloda, ekonomik büyümeyi sağlamak için cari açık verilmesi gerekli hale gelebilmektedir. Nihayetinde, ekonomik yapının sağlıklı bir yapıya kavuşabilmesi ve dış finansman bağımlılığının sebep olduğu tahribatın düzeltilebilmesi çok zaman almakta ve toplum olarak yüksek bedeller ödenmektedir.

Bu bağlamda, ulusal sanayi tahrip olmadan ve kriz sürecine girilmeden, sermaye hareketlerine yönelik kimi kontrol mekanizmalarının ve önlemlerin alınması öncelikli hedef olarak kabul edilmelidir. Söz konusu önlemler; başta para ve maliye politikaları olmak üzere Tobin vergisi diye de bilinen olarak bazı vergisel düzenlemeler olarak tanımlanmaktadır.

Yeterli kaynağa sahip olmayan ve ekonomik kalkınmayı hedef seçen bir ülke; uzun vadeli, kalıcı, istihdam yaratan ve aynı teknoloji getiren doğrudan yabancı sermayeye yönelik yatııı ortamını tesis etmelidir. Doğrudan yabancı sermayenin ülkeye girişi sonucu, ülkeler ihtiyaç duydukları finansmana kavuşurken; reel sektör üretim gücüne, istihdam ve teknoloji kaynaklı rekabet avantajına kavuşabilmektedir. Günümüzde bazı ülkeler doğrudan yabancı sermayeyi teşvik edebilmek için vergi indirimi, arazi tahsisi ve bürokratik kolaylıklar vb. araçları kullanmaktadır. Yüzde 14 seviyelerinde bulunan tasarruf oranları nedeniyle ekonomik büyüme için dış kaynak gereksinimi içinde olan Türkiye'nin de önceliği doğrudan yabancı sermayeyi teşvik edici yatırım ortamını temin etmek olmalıdır. Bu bağlamda bir başka önemli faktör ise, özelleştirme kapsamındaki satın almalar dışında, bir başka deyişle ülkede sıfırdan yeni bir tesis kurmak amacıyla gelen doğrudan yabancı sermayeye yönelik teşvik politikalarının uygulanmasıdır.

Kısa vadeli yabancı sermayeye bağımlı olmamak ve sermayenin ülkeden çıkışı durumunda olumsuz etkileri ortadan kaldırmak için bazı tedbirlerin alınmasının gerekli olduğu görülmektedir. Günümüzde, söz konusu önlemler konusunda akademik çevrelerde uzlaşma olmasa da; faiz oranları başta olmak üzere maliye ve para politikaları ile öncelikli olarak Tobin vergisi olmak üzere diğer vergi sistemleri de sorgulanmaktadır.

Yapısal reformların yapılması ve bu konuda uygulayıcılar ile toplumun geniş kesimlerinin uzlaşması ve olumlu sonuç alınması güç ve uzun vadeli bir süreçtir. Bu bağlamda, hükümet ve merkez bankası yetkilerinin ekonomide kısa vadeli getirilerden ziyade uzun vadeye odaklanmaları ve acı reçete de olsa uygulama konusunda kararlılık göstermeleri gerekmektedir. Kısa vadeli kazançların baskın olması halinde ise, ülke ekonomileri kısa vadeli dış finansmana bağıı kalmakta ve krizlere davetiye çıkarılmaktadır.

Sonuç olarak; doğrudan yabancı sermaye ve/veya iç kaynaklarla finanse edilen bir ekonomik kalkınma ve büyüme modelinin benimsenmesi halinde Türkiye, Güney Kore örneğinde olduğu gibi dünyanın büyük ekonomileri arasında yer edinme potansiyeline sahip bir ülkedir.

\section{KAYNAKÇA}

Acemoğlu,D. (2009). Introduction to Modern Economic Growth, New Jersey: Princeton University Press.

Brookings Institute, (2011, September). Rethinking Central Banking, Committee on International Economic Policy.

Calvo, G. A. (1998). Capital Flows and Capital Market Crisis: The Simple Economics of Sudden Stops, Journal of Applied Economics, 1(1): 3554.

Calvo, G. A. Izquierdo, A. Mejia, L.F. (2004). On the Empirics of Sudden Stops: The Relevance of Balance Sheets Effects, NBER Working Paper, 10520, 22-46.

Cassidy, J. (2009). How Markets Fail: The Logic of Economic Calamities. New York, NY: Farrar, Straus and Giroux.

Chang, H.J. (1994). The Political Economy of Industrial Policy. New York, NY: St. Martin's Press.

Kaminsky, G. L. Vega-Garcia, P. (2014, April). Variaties of Sovereign Crises: Latin America 1820-1931, NBER Working Paper Series, 20042, 41-56.

Magud, N. E., Carmen M. R., Rogoff, K. S. (2011, February). Capital Controls : Myth and Reality-A Portfolio Balance Approach, NBER Working Paper, 12-27.

Magud, N.E. Reinhart, C. M. Vesperoni, E.R. (2012, February). Capital Inflows, Exchange Rate Flexibility and Credit Booms, IMF Working Paper, 19-32.

Magud, N. Reinhart, C. M. Rogoff, K. (2011). Capital Controls : A Meta Evaluation Approach, Peterson Institute for International Economics, (Çevrimiçi), https://mpra.ub.uni-muenchen.de/30274/

Minsky, H.P. (1993). The Financial Instability Hypothesis. Radical Political Economy, Ed. by Philip Arestis, Malcom Sawyer, NY: Edward Elgar Aldershot.

Montiel, P. J. (2013, May). Capital Flows : Issues and Policies, Inter-American Development Bank Working Paper Series, IDB-WP-411,11-28. 
Montiel, P. Reinhart, C. M. (1999, August). Do Capital Controls and Macroeconomic Policies Influence the Volume and Composition of Capital Flows ? Evidence from 1990's , Journal of International Money and Finance, 18( 4), 624-648.

Paya, M. M. (2013). Küresel Ortamda İktisat Politikaları. İstanbul: Türkmen Kitabevi.

Reinhart C. M., Rogoff, K. S. (2004) Serial Default and the Paradox of Rich to Poor Capital Flows, American Economic Review, 94(2) : 52-58.

Reinhart C. M., Rogoff, K. S. (2013, December). Financial and Sovereign Debt Crises : Some Lessons Learned and Those Forgotten, IMF Working Paper, WP/13/266.

Rodrik, D. (2007). One Economics Many Recipes : Globalization, Institutions and Economic Growth, New Jersey : Princeton University Press.

Shuhan, P. Claessens, S. Mamingi, N. (1993, July). Equity of Bond Flows to Asia and Latin America The Role of Global and Country Factors, WPS 1160, International Economics Department, The World Bank.

Sula, O. Willett, T. D. ( 2006). The Reversibility of Different Types of Capital Flows to Emerging Markets, MPRA Paper, 384, University Library of Munich, Germany, (Çevrimiçi), http://mpra.ub.uni-muenchen.de/ 